\title{
Thermal conductivity as influenced by the temperature and apparent viscosity of dairy products
}

\author{
B. J. Gonçalves, C. G. Pereira, A. M. T. Lago, C. S. Gonçalves, T. M. O. Giarola, L. R. Abreu, \\ and J. V. Resende ${ }^{1}$ \\ Department of Food Science, Federal University of Lavras, 37200-000, Lavras, MG, Brazil
}

\section{ABSTRACT}

This study aimed to evaluate the rheological behavior and thermal conductivity of dairy products, composed of the same chemical components but with different formulations, as a function of temperature. Subsequently, thermal conductivity was related to the apparent viscosity of yogurt, fermented dairy beverage, and fermented milk. Thermal conductivity measures and rheological tests were performed at 5, 10, 15, 20, and $25^{\circ} \mathrm{C}$ using linear probe heating and an oscillatory rheometer with concentric cylinder geometry, respectively. The results were compared with those calculated using the parallel, series, and Maxwell-Eucken models as a function of temperature, and the discrepancies in the results are discussed. Linear equations were fitted to evaluate the influence of temperature on the thermal conductivity of the dairy products. The rheological behavior, specifically apparent viscosity versus shear rate, was influenced by temperature. Herschel-Bulkley, power law, and Newton's law models were used to fit the experimental data. The Herschel-Bulkley model best described the adjustments for yogurt, the power law model did so for fermented dairy beverages, and Newton's law model did so for fermented milk and was then used to determine the rheological parameters. Fermented milk showed a Newtonian trend, whereas yogurt and fermented dairy beverage were shear thinning. Apparent viscosity was correlated with temperature by the Arrhenius equation. The formulation influenced the effective thermal conductivity. The relationship between the 2 properties was established by fixing the temperature and expressing conductivity as a function of apparent viscosity. Thermal conductivity increased with viscosity and decreased with increasing temperature.

Key words: yogurt, fermented milk, thermal conductivity, rheology

Received September 26, 2016.

Accepted January 8, 2017.

${ }^{1}$ Corresponding author: jvresende@dca.ufla.br

\section{INTRODUCTION}

Technological advances have supported the development of new dairy products while the dairy market has registered sustained and continuous growth (Nagpal et al., 2012; Masson et al., 2016). Food engineering within the dairy sector is an expanding field of study, which results in significant improvements in product quality and greater knowledge of ingredients and their influence on chemical composition, structure, and rheological and sensory properties (Chandrapala and Zisu, 2016). Although technological processes such as fermentation are traditionally used, the dairy sector has developed techniques to produce a diverse range of milk-based products and dairy ingredients (Nagpal et al., 2012).

Yogurt, fermented dairy beverages, and fermented milk all have the same components (water, protein, fats, carbohydrate, and ash) but in different contents in their intrinsic composition (Reddy and Datta, 1994; Minim et al., 2002; Munir et al., 2016). Yogurt is formed during the slow lactic fermentation of milk lactose by thermophilic lactic acid bacteria (Park and Haenlein, 2013; Shori and Baba, 2014). The resulting lactic acid reacts with milk protein, promoting the characteristic texture of this product (Serafeimidou et al., 2013). Fermented dairy beverages are dairy products resulting from the mixing of milk and whey, vegetable fat, fermented milk, lactic acid starter culture, and other dairy products. The milk base represents at least $51 \%$ (vol/ vol) of the total ingredients of the product, fermented by a specific microorganism culture (Brazil, 2005). From the technological viewpoint, the main difference between yogurt and fermented dairy beverages is the addition of whey to the latter, which results in lower viscosity (Castro et al., 2013). Fermented milk means a lactic product where fermentation involves the action of lactic acid bacteria and results in coagulation and a reduction in $\mathrm{pH}$. According to legislation, the cultures or microorganisms used in the fermentation define the name of the product to be yogurt or fermented milk (Brazil, 2007; Park and Haenlein, 2013). It is evident that the technology for the manufacture of fermented 
Table 1. Chemical composition of the dairy products

\begin{tabular}{lccccccc}
\hline & \multicolumn{7}{c}{ Composition (\%) } \\
\cline { 2 - 7 } Product & Moisture & Protein & Fat & Carbohydrate & \multirow{2}{*}{ Fiber } & \multirow{2}{*}{ Ash } \\
\hline Yogurt & 60.48 & 5.10 & 4.23 & 30.00 & 0.00 & 0.18 \\
Fermented dairy beverage & 68.17 & 3.53 & 3.36 & 24.66 & 0.00 & 0.25 \\
Fermented milk & 86.82 & 1.51 & 0.00 & 11.48 & 0.00 & 0.08 \\
\hline
\end{tabular}

milk is very similar to the production of yogurt; however, low viscosity is a desirable and notable feature of fermented milk (Tamime, 2006).

In food processing, correct dimensioning of the equipment used, better understanding of food structural organization, and process optimization all depend on accurate data of the thermal properties and rheological behaviors of the products as well as their behaviors during the process as a function of temperature to ensure the high quality of the final product (Ahmed et al., 2005; Moura et al., 2005; Mercali et al., 2011; Augusto et al., 2012). Another important application of thermal properties is accurate modeling and simulation of industrial processes, which are useful for the prediction of process behavior and critical for decision making and optimization without putting the real process at risk. However, these thermal properties are worked separately using empirical models derived from experimental results and require more computational effort (Munir et al., 2016). Thermal conductivity is considered the most important property in thermal processing at high and low temperatures (Muramatsu et al., 2005; Carson, 2006), and there is a correlation between the apparent viscosity and thermal conductivity (Pereira et al., 2014) because shear rate is related to thermal conductivity, and these 2 variables vary with intrinsic composition and temperature. For this reason, it is important to characterize the rheological properties and study models that describe the rheological behavior as a function of the temperature used during processing (Nindo et al., 2007). The viscosity of dairy products is important in regard to sensory perceptions of food products (Sodini et al., 2004; Walstra et al., 2006).

The thermal conductivity of fluid dairy products increases linearly with increasing temperature and decreases with increasing total solid contents (Reddy and Datta, 1994; Minim et al., 2002; Munir et al., 2016). The flow behavior and apparent viscosity also vary with temperature (Penna et al., 2001; Munir et al., 2016); an increase in temperature causes a decrease in the viscosity of the liquid phase, increasing the movement of particles in suspension (Pelegrine et al., 2000). There is a great need for thermal conductivity values and apparent viscosity results of these dairy products for processing, preservation, and production. Given the above, the aims of this study were to evaluate the influence of temperature on thermal conductivity and apparent viscosity of yogurt, fermented dairy beverages, and fermented milk and to develop mathematical models from experimental measures that correlate their thermal conductivity and apparent viscosity.

\section{MATERIALS AND METHODS}

\section{Sample Acquisition and Chemical Composition}

Yogurt, fermented dairy beverages, and fermented milk were purchased in the local market in the municipality of Lavras, Brazil. The composition of yogurts, fermented dairy beverages, and fermented milks in ranged from 2.00 to $3.11 \%$ protein, 0 to $2.94 \%$ fat, 11.11 to $15.90 \%$ carbohydrate, $0 \%$ fiber, 0.10 to $0.13 \%$ ash, and 77.92 to $85.29 \%$ water, as shown in Table 1 . According to the information from the yogurt manufacturers, the samples tested had modified starch plus gelatin added. The fermented dairy beverages had modified starch plus pectin added. The chemical composition of the 3 commercial products were obtained from their labels.

\section{Experimental Measurements of Thermal Conductivity}

Thermal conductivity measurements were performed using a hot wire probe, also known as a transient-state method. In this technique, the heat is transferred to the material through the probe. The probe is resistively heated at a constant rate using a source that provides a continuous electrical current, and then it is possible to determine the thermal conductivity of a food experimentally (Dawson et al., 2006). The probe was constructed from a hypodermic needle with an external diameter of $0.6 \mathrm{~mm}$ and a length of $70 \mathrm{~mm}$, into which was placed a resistance heating wire (nickel-chromium; Omega Engineering Inc., Stamford, CT) with a length of $0.36 \mathrm{~m}$ and diameter of $0.08 \mathrm{~mm}$, together with a small type-T thermocouple AWG 30 (Omega Engineering Inc.) located at the exact center of the probe. All components were insulated with epoxy resin. By apply- 
ing heat via the resistance of the hot wire probe using a current source, a temperature increase was recorded through a signal conditioning system (National Instruments Mod SCXI, Budapest, Hungary) using LabView 8.5 software (National Instruments, Newbury, Ireland) with $1.0 \mathrm{~s}$ intervals between each recording. A thermostatic bath (model 521/3DENova Ética, Sao Paulo, Brazil) was used to stabilize sample temperatures at 5 to $25^{\circ} \mathrm{C}$.

\section{Mathematical Analysis of the Hot Wire Probe Method}

The usual procedure for measuring thermal conductivity by heating a linear sensor is based on applying a constant heat flux from the heat source to the material initially in thermal equilibrium, thereby generating a variation in temperature, $T_{0}$ to $T$, at some point of the material (Park et al., 1997). This temperature change $(\Delta)$ can be expressed by Eq. [1]:

$$
\Delta T=T-T_{0}=\frac{q}{4 \pi k}\left[\ln \left(\frac{t}{t_{0}}\right)\right],
$$

where $T=$ temperature $\left({ }^{\circ} \mathrm{C}\right), T_{0}=$ initial temperature $\left({ }^{\circ} \mathrm{C}\right), q=$ power per meter $\left(\mathrm{W} \cdot \mathrm{m}^{-1}\right), k=$ thermal conductivity $\left(\mathrm{W} \cdot \mathrm{m}^{-1} \cdot \mathrm{K}^{-1}\right), t=$ time $(\mathrm{s})$, and $t_{0}=$ initial time (s).

The power per meter supplied $(q)$ was determined by Eq. [2]:

$$
q=\frac{P}{L}=\frac{R \cdot i^{2}}{L}
$$

where $P=$ source power $(\mathrm{W}), R=$ electrical resistance $\left(\Omega \cdot \mathrm{m}^{-1}\right), i=$ electrical current $(\mathrm{A})$, and $L=$ length of the electric resistance wire inside the probe $(\mathrm{m})$.

Thermal conductivity was determined by Eq. [3], with the slope $(m)$ obtained from the linear relation between the displacement $\left(T-T_{0}\right)$ and $\ln \left(t / t_{0}\right)$ (Brock et al., 2008):

$$
m=\frac{q}{4 \pi k} .
$$

Probe Calibration. Before determining the thermal conductivity, the probe was calibrated in relation to temperature, and a linear equation was obtained for its adjustment. In addition to the temperature calibration, the probe was calibrated using a $40 \%$ sucrose solution (wt/vol) having a known thermal conductivity $(k)$ in the temperature range relating to the operation of the probe. From the calibration, we determined a correction factor $f$, as shown in Eq. [4]:

$$
f=\frac{k_{\text {theoretical }}}{k_{\text {experimental }}} \text {. }
$$

The values of $k_{\text {theoretical }}$ for sucrose solutions were obtained from ASHRAE (2002) for 5, 10, 15,20 , and $25^{\circ} \mathrm{C}$.

Theoretical Models for Predicting Thermal Conductivity. In the unfrozen state, effective thermal conductivity can be predicted from the intrinsic thermal conductivity combined with a suitable heat transfer model and volumetric fraction of each component. The intrinsic thermal conductivity of each component combined with the respective volume fractions provides the determination of the thermal conductivity of the food as a whole, as shown in Eq. [5]:

$$
k_{e}=f\left(k_{1}, k_{2}, k_{3}, \ldots, X_{1}, X_{2}, X_{3}, \ldots\right)
$$

where $k_{e}$ is the effective thermal conductivity; $k_{1}, k_{2}$, $k_{3}, \ldots$ are the values of the intrinsic thermal conductivities of the components; and $X_{1}, X_{2}, X_{3}, \ldots$ are the volumetric fractions (Miyawaki and Pongsawatmanit, 1994).

The volumetric fractions are determined by Eq. [6]:

$$
X_{i}=\frac{\left(x_{i} / \rho_{i}\right)}{\sum\left(x_{i} / \rho_{i}\right)},
$$

where $x_{i}$ is the mass fraction of each component, $\rho_{i}$ is the density of each pure component (protein, ash, fiber, carbohydrate, fat, water; $\mathrm{kg} \cdot \mathrm{m}^{-3}$ ), and $\Sigma X_{i}=1$.

The equations for the determination of the thermal conductivities and densities of the pure components are obtained from ASHRAE (2002). The theoretical models used to predict the thermal conductivity of the dairy products were parallel, series, and Maxwell-Eucken. In the parallel model, thermal conductivity is calculated by multiplying the sum of the thermal conductivity by the volumetric fraction of each component according to Eq. [7]. In the model in series, Eq. [8], the phases are in series or in the direction perpendicular to heat flow, which causes high resistance to its passage through the sample. The Maxwell-Eucken model, represented by Eq. [9], is a combination of the series and parallel models, so it has a resistance intermediate between them (Miyawaki and Pongsawatmanit, 1994; Pereira et al., 2013; Giarola et al., 2016):

$$
k_{p a}=\sum_{i=1}^{n} X_{i}^{v} k_{i}
$$




$$
\begin{gathered}
\frac{1}{k_{s e}}=\sum_{i=1}^{n} \frac{X_{i}^{v}}{k_{i}}, \\
k_{m e}=k_{c}\left\{\frac{k_{d}+2 k_{c}-2 X_{d}^{v}\left(k_{c}-k_{d}\right)}{k_{d}+2 k_{d}+X_{c}^{v}\left(k_{c}-k_{d}\right)}\right\},
\end{gathered}
$$

where $k_{p a}, k_{s e}$, and $k_{m e}$ are the conductivities of the parallel, serial, and Maxwell-Eucken models, respectively; $i$ refers to the pure components (protein, ash, fiber, carbohydrate, fat, water); $n$ is the number of components; $k_{c}$ is the conductivity of the continuous phase; and $k_{d}$ is the conductivity of the dispersed phase.

Errors Between Theoretical and Experimental Conductivity. The effective thermal conductivities of the dairy products were compared with the theoretical values obtained by mathematical models. A percentage error was calculated using Eq. [10], which allowed us to determine the model that best fitted the effective thermal conductivities:

$$
\% \text { Error }=\left|\frac{\left(k_{\text {experimental }}-k_{\text {theoretical }}\right)}{k_{\text {theoretical }}}\right| \times 100 \text {. }
$$

Rheological Behavior. The rheological behavior of the dairy products was evaluated at $5,10,15,20$, and $25^{\circ} \mathrm{C}$ using a Haake rheometer ReoStress 6000 (Thermo Scientific, Karlsruhe, Germany), equipped with a Haake A10 thermostatic bath (Thermo Scientific) and a Haake UTM Controller universal temperature control system (Thermo Scientific), coupled to a set of concentric cylindrical geometry sensors (CC25 DIN Ti and CCB25 DIN) with a gap of $5.300 \mathrm{~mm}$ for all samples. The cup had a diameter (D) of $27.201 \mathrm{~mm}$, and the rotor used had the following specifications: length $\mathrm{L}=$ $37.603 \mathrm{~mm}$, diameter $\mathrm{D}=25.079$, cone angle $\beta=120^{\circ}$, and sample volume $\mathrm{V}=16.1 \mathrm{~mL}$.

Given the thixotropy, to eliminate the influence of time on the flow behavior of products, each sample was subjected to a continuous ramp shear rate from 0 to $300 \mathrm{~s}^{-1}$ over $3 \mathrm{~min}$ for the up-sweep and $3 \mathrm{~min}$ for the downward curve. After this procedure, a flow curve was generated for the rheological characterization of each sample, which involved applied shear rates from 0 to $300 \mathrm{~s}^{-1}$ for a period of $3 \mathrm{~min}$ for each of the tested temperatures. The experimental flow curve data (shear stress vs. shear rate) were adjusted to the power law (Eq. [11]), Herschel-Bulkley (Eq. [12]), and Newton's law (Eq. [13]) models:

$$
\sigma=K \dot{\gamma}^{n}
$$

$$
\begin{gathered}
\sigma=\sigma_{0}+K \dot{\gamma}^{n}, \\
\sigma=\mu \dot{\gamma},
\end{gathered}
$$

where $\sigma=$ shear stress $(\mathrm{Pa}), \sigma_{0}=$ yield stress $(\mathrm{Pa}), \dot{\gamma}=$ shear rate $\left(\mathrm{s}^{-1}\right), K=$ consistency index $(\mathrm{Pa} \cdot \mathrm{s}), n=$ flow behavior index, and $\mu=$ Newtonian viscosity $(\mathrm{Pa} \cdot \mathrm{s})$. The experiments were done in 3 repetitions, with each repetition analyzed in triplicate.

Effect of Temperature on Apparent Viscosity. According to Steffe (1996), the rheological behavior of fluid foods is complex and influenced by numerous factors; Eq. [14] allows the prediction of apparent viscosity based on shear rate and temperature. The equation is similar to the Arrhenius model, and it was used to assess the effect of temperature on the apparent viscosity of the different products analyzed. Viscosity was determined at a fixed shear rate of $27.27 \mathrm{~s}^{-1}$ :

$$
\ln \eta_{a}=B+\left(\frac{E_{a}}{R}\right) T^{-1}
$$

where $\eta_{a}$ is the apparent viscosity $(\mathrm{Pa} \cdot \mathrm{s}) ; B$ is the parameter adjustment; $E_{a}$ is the activation energy $\left(\mathrm{J} \cdot \mathrm{mol}^{-1}\right)$; $R$ is the gas constant $\left(8.314 \mathrm{~J} \cdot \mathrm{g}^{-1} \cdot \mathrm{mol}^{-1} \cdot \mathrm{K}^{-1}\right)$; and $T$ is the absolute temperature $(\mathrm{K})$.

\section{Statistical Analysis}

The fit of the experimental data to the rheological models was performed using SAS software (version 9.1.2, 2008; SAS Institute Inc., Cary, NC). The influence of temperature on rheological parameters was assessed by ANOVA and linear regression using Origin 8.0 (Origin Lab Inc., Northampton, MA). This software was also used to graph thermal conductivities as a function of apparent viscosities using exponential fitting. R-squared (coefficient of determination) and $P$-values from ANOVA were used to evaluate the adjustment quality.

\section{RESULTS AND DISCUSSION}

\section{Probe Calibration}

The probe was calibrated in relation to the temperature by correlation between the temperatures measured experimentally and those obtained by thermometer. Temperature calibration was carried out using the linear equation obtained (data not shown), which had a coefficient of determination $\left(\mathrm{R}^{2}\right)$ of 0.999 . Table 2 shows the correction factors and the experimental and 
Table 2. Experimental and theoretical values for thermal conductivity of $40 \%$ sucrose solutions

\begin{tabular}{|c|c|c|c|c|}
\hline \multirow{2}{*}{$\begin{array}{l}\text { Temperature } \\
\left({ }^{\circ} \mathrm{C}\right)\end{array}$} & \multirow{2}{*}{$\begin{array}{l}\text { Slope } \\
(m)^{1}\end{array}$} & \multicolumn{2}{|c|}{ Thermal conductivity $\left(\mathrm{W} \cdot \mathrm{m}^{-1} \cdot \mathrm{K}^{-1}\right)$} & \multirow[b]{2}{*}{ Factor $f^{2}$} \\
\hline & & Experimental $^{3}$ & Theoretical $^{4}$ & \\
\hline 0 & 4.606 & $0.181( \pm 0.003)$ & 0.443 & 2.454 \\
\hline 20 & 4.166 & $0.199( \pm 0.002)$ & 0.470 & 2.355 \\
\hline 50 & 3.997 & $0.208( \pm 0.006)$ & 0.502 & 2.413 \\
\hline 80 & 3.826 & $0.217( \pm 0.008)$ & 0.525 & 2.416 \\
\hline Average & & & & 2.410 \\
\hline
\end{tabular}

theoretical results obtained at each temperature for the thermal conductivity of the sucrose solution.

An $f$ factor of 2.410 was used for the correction of the experimental thermal conductivities of the dairy products analyzed.

\section{Thermal Conductivity}

Figure 1a shows the experimental results for temperature variation versus time due to the heating provided by the probe inserted into the center of the stabilized sample of fermented milk at $40^{\circ} \mathrm{C}$. Figure $1 \mathrm{~b}$ shows the experimental results of temperature increase versus the logarithm of time used to obtain the parameter $m$ (slope) and thermal conductivities.

Figure 2 shows the variation of the thermal conductivity of the 3 dairy products for the temperature range from 278.15 to $298.15 \mathrm{~K}$. It can be seen that, for the same temperature range, yogurts have the lowest thermal conductivity values. Fermented milks and fermented dairy beverages have higher values of thermal conductivity, which are related to their water contents. Water is the food component that contributes most to the increase in conductivity. Various studies (Reddy and Datta, 1994; Tavman and Tavman, 1999; Minim et al., 2002; Pereira et al., 2013) have confirmed the strong correlation between thermal conductivity and water contents of dairy products. In these studies, it was observed that the thermal conductivity of all dairy products tested increased linearly with increasing temperature and water content. Tavman and Tavman (1999) also reported that in all dairy products, except butter, there is a linear reduction in thermal conductivity with an increase in the protein content. This trend was also observed in this work as shown in Tables 1 and 3.

For all studied products, we detected an increase in thermal conductivity with increasing temperature. From Figure 2, it was possible to adjust the linear equations [15], [16], and [17], which describe the behavior of the thermal conductivities in the temperature range of 278.15 to $298.15 \mathrm{~K}$ of yogurt, fermented dairy beverage, and fermented milk, respectively:

$$
\text { Yogurt: } k=0.0017 T-0.0258 ; \mathrm{R}^{2}=0.9844,
$$

Fermented dairy beverage: $k=0.0010 T-0.2297$;

$$
\mathrm{R}^{2}=0.9589
$$

Fermented milk: $k=0.0017 T-0.0255$;

$$
\mathrm{R}^{2}=0.9908 \text {. }
$$

\section{Thermal Conductivity Obtained Through the Theoretical Models}

In addition to the experimental measurements, the thermal conductivities of dairy products were evaluated using the series, parallel and Maxwell-Eucken models present in the literature. In these models, because foods are made of a mixture of carbohydrates, proteins, ash, fat, water, and other components that have their intrinsic conductivities, they together give rise to the thermal conductivity of the food as a whole (Miyawaki and Pongsawatmanit, 1994). Figure 3 shows the comparison between the thermal conductivities for yogurt obtained experimentally and by using the theoretical models.

In Figure 3, it can be seen that the series model best fit the experimental data compared with the other 2 models (parallel and Maxwell-Eucken). The same was observed for the fermented milk and fermented dairy beverages (data not shown). Comparisons between the experimental and predicted results and the errors associated with each temperature are shown in Table 3.

The series model gave the best fit of the experimental data for all dairy products analyzed, with a maximum error of $3.45 \%$ for yogurt, $2.66 \%$ for fermented dairy beverages, and $5.94 \%$ for fermented milk. The error for fitting the series model was about 1.72 and 2.23 times 
higher in fermented milk than in yogurt and fermented dairy beverages, respectively. This can be explained by differences in product viscosities, which influence the heat transfer process between the probe and product during measurement of the thermal conductivity. The low viscosity of fermented milk leads to more intense convective currents in the fluid near the heated probe surface. These currents increase the heat transfer rate, resulting in higher values of experimental thermal conductivity and higher error values compared with the predicted value. Miles et al. (1983) tested the robustness of model equations by comparing the measured and calculated thermal conductivities for 11 foods.
They found small deviations (approximately 10\%) between measured and calculated values. They claimed that such accuracy is acceptable or useful for most food engineering heat transfer calculations.

\section{Rheological Behavior}

Among the models used to describe the rheological behavior of dairy products, the Herschel-Bulkley, the power law, and Newton's law models provided the best statistical parameters for the adjustment of the experimental data for yogurt, fermented dairy beverages, and

(a)

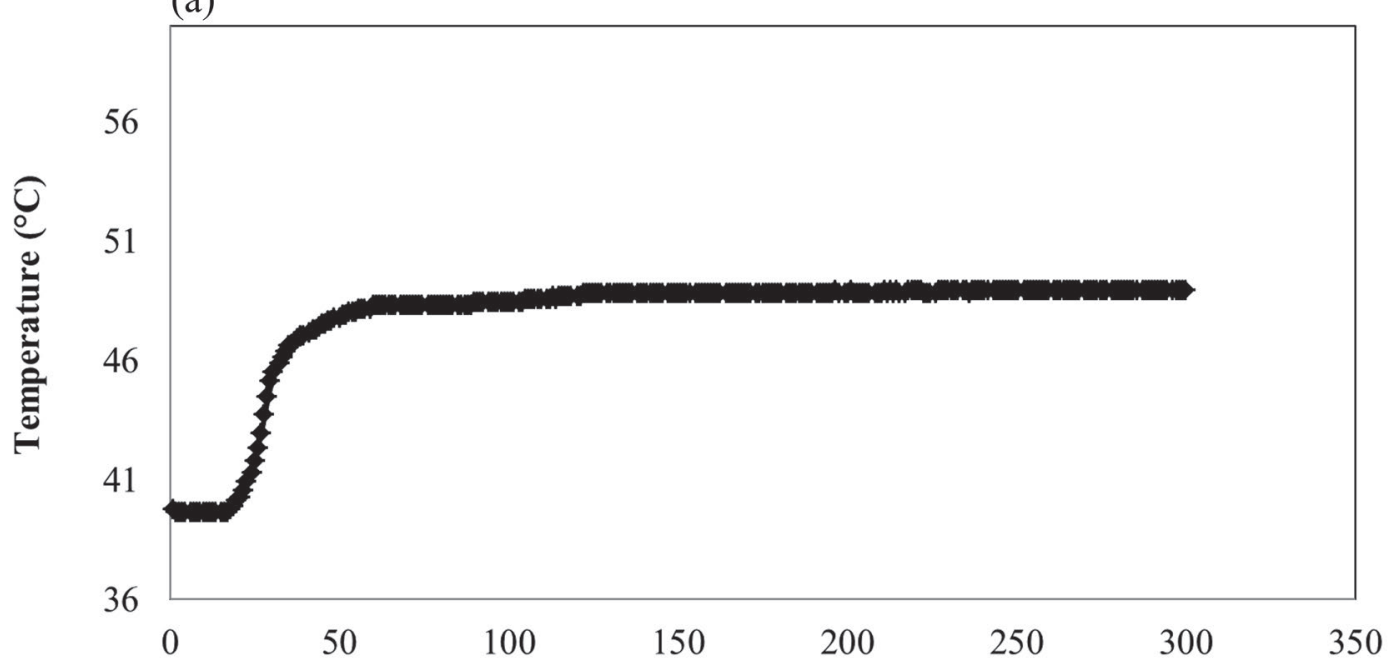

Time (s)

(b)

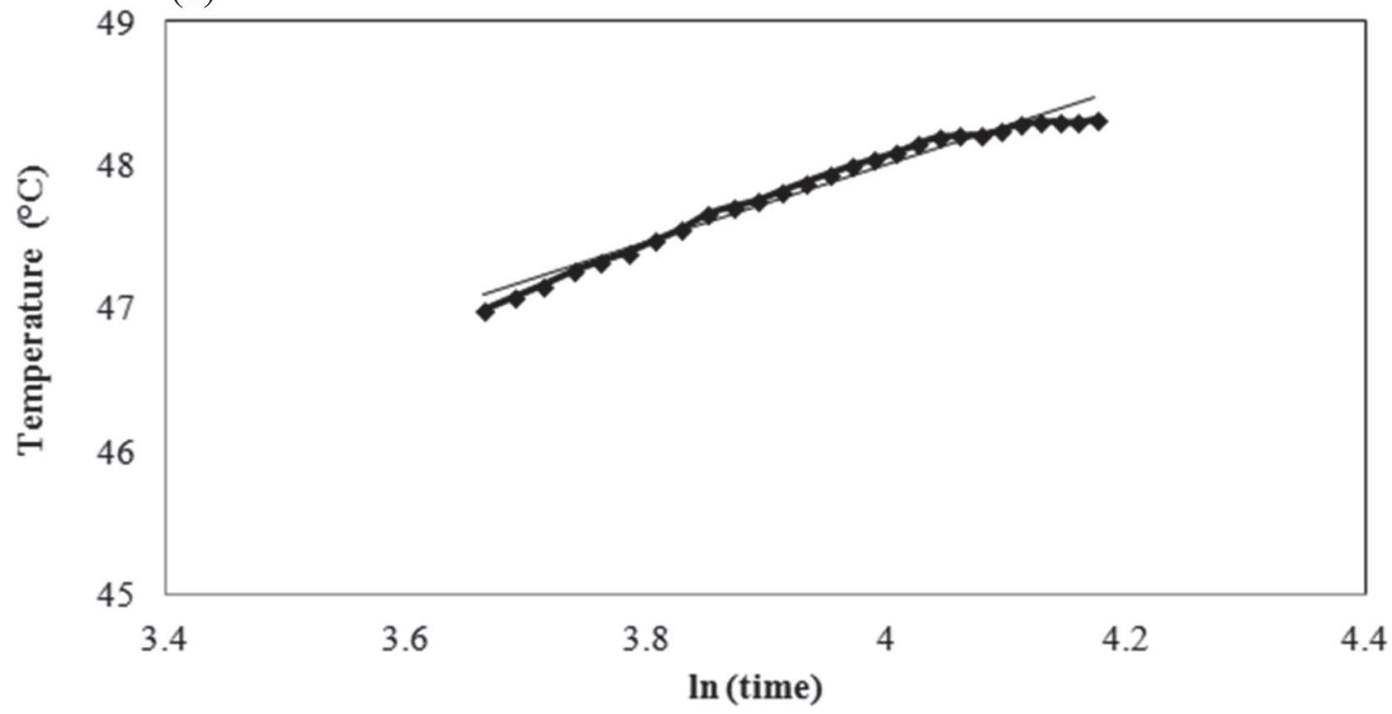

Figure 1. (a) Experimental results of temperature variation as a function of time during the insertion of the heating probe in the sample of fermented milk stabilized at $40^{\circ} \mathrm{C}$; (b) linearization of temperature increase data for fermented milk sample initially stabilized at $40^{\circ} \mathrm{C}$. 


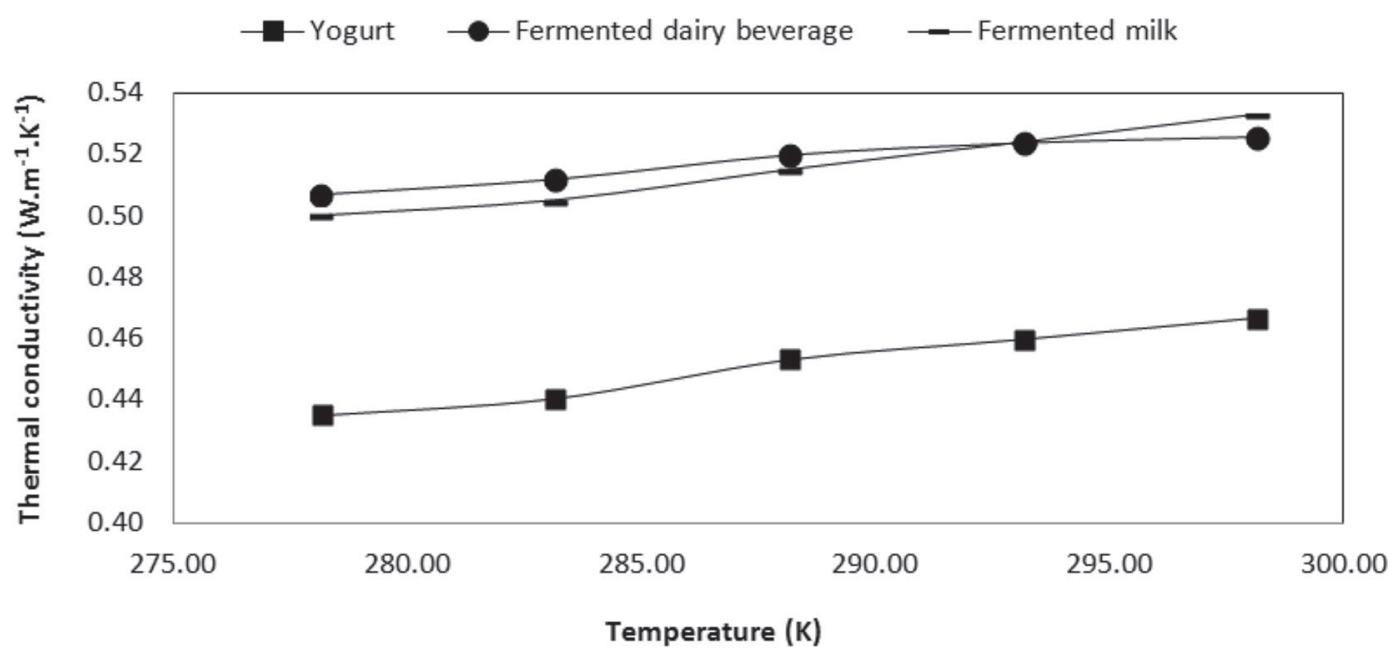

Figure 2. Experimental thermal conductivity for dairy products.

fermented milk, respectively. Karsheva et al. (2013), working with rheological properties of yogurts during storage, found that the Herschel-Bulkley model gives better accuracy. Regarding fermented dairy beverages, Penna et al. (2001) described the power law model as the most suitable to describe the rheological behavior of 5 commercial brands of fermented dairy beverage.

As shown in Table 4, the rheological parameters determined according to each model used were (1) consistency index $(K)$, flow behavior index $(n)$, and initial yield stress $\left(\tau_{0}\right)$ from the Herschel-Bulkley model; (2) $K$ and $n$ from the power law; and (3) Newtonian viscosity $(\mu)$ from Newton's law. Regarding the adjustment of the experimental points, the studied models were adequate, as shown by the values of $\mathrm{R}^{2}$ (coefficient of determination) and root mean square error (RMSE) presented in Table 4.

For the rheological parameters obtained for yogurt using the Herschel-Bulkley model, we found that the correlation between yield stress and consistency index versus temperature was significant $(P<0.05)$. The correlation of values of $K$ as a function of temperature obtained by the power law model for fermented dairy beverages was also significant $(P<0.05)$, and the different temperatures studied influenced these parameters. For fermented milk, the viscosity data $(\mu)$ determined by Newton's law was significant $(P<0.05)$ for all temperatures tested.

Table 3. Comparison between experimental and predicted results for thermal conductivity $(k)$ of dairy products ${ }^{1}$

\begin{tabular}{|c|c|c|c|c|c|c|c|}
\hline Temperature $\left({ }^{\circ} \mathrm{C}\right)$ & $\begin{array}{c}k_{\text {experimental }} \\
\left(\mathrm{W} \cdot \mathrm{m}^{-1} \cdot \mathrm{K}^{-1}\right)\end{array}$ & $\begin{array}{c}k_{\text {parallel }} \\
\left(\mathrm{W} \cdot \mathrm{m}^{-1} \cdot \mathrm{K}^{-1}\right)\end{array}$ & $\begin{array}{l}\text { Error } \\
(\%)\end{array}$ & $\begin{array}{c}k_{\text {series }} \\
\left(\mathrm{W} \cdot \mathrm{m}^{-1} \cdot \mathrm{K}^{-1}\right)\end{array}$ & $\begin{array}{l}\text { Error } \\
(\%)\end{array}$ & $\begin{array}{l}k_{\text {Maxwell-Eucken }} \\
\left(\mathrm{W} \cdot \mathrm{m}^{-1} \cdot \mathrm{K}^{-1}\right)\end{array}$ & $\begin{array}{l}\text { Error } \\
(\%)\end{array}$ \\
\hline \multicolumn{8}{|l|}{ Yogurt } \\
\hline 15 & $0.453( \pm 0.005)$ & 0.538 & 18.76 & 0.462 & 1.99 & 0.524 & 15.67 \\
\hline 20 & $0.460( \pm 0.002)$ & 0.544 & 18.26 & 0.467 & 1.52 & 0.530 & 15.22 \\
\hline 25 & $0.467( \pm 0.003)$ & 0.551 & 17.99 & 0.472 & 1.07 & 0.537 & 14.99 \\
\hline 10 & $0.512( \pm 0.006)$ & 0.561 & 9.57 & 0.520 & 1.56 & 0.555 & 8.40 \\
\hline 15 & $0.520( \pm 0.005)$ & 0.569 & 9.42 & 0.527 & 1.35 & 0.562 & 8.08 \\
\hline 20 & $0.524( \pm 0.002)$ & 0.576 & 9.92 & 0.534 & 1.91 & 0.569 & 8.59 \\
\hline 25 & $0.526( \pm 0.005)$ & 0.583 & 10.84 & 0.540 & 2.66 & 0.576 & 9.51 \\
\hline \multicolumn{8}{|l|}{ Fermented milk } \\
\hline 5 & $0.500( \pm 0.003)$ & 0.559 & 11.80 & 0.527 & 5.40 & 0.554 & 10.80 \\
\hline 10 & $0.505( \pm 0.006)$ & 0.567 & 12.28 & 0.535 & 5.94 & 0.562 & 11.29 \\
\hline
\end{tabular}

${ }^{1} k_{\text {experimental }}=$ experimental thermal conductivity; $k_{\text {parallel }}=$ thermal conductivity obtained through the parallel model; $k_{\text {series }}=$ thermal conductivity obtained through the series model; $k_{\text {Maxwel-Eucken }}=$ thermal conductivity obtained through the Maxwell-Eucken model. Values are mean \pm SD. 
Table 4. Rheological parameters ${ }^{1}$ for dairy products

\begin{tabular}{|c|c|c|c|c|c|c|}
\hline Product & $\begin{array}{l}\text { Temperature } \\
\left({ }^{\circ} \mathrm{C}\right)\end{array}$ & \multicolumn{5}{|c|}{ Herschel-Bulkley (HB) } \\
\hline Yogurt & $\begin{array}{l}5 \\
10 \\
15 \\
20 \\
25\end{array}$ & $\begin{array}{c}1.236( \pm 0.363) \\
1.201( \pm 0.446) \\
1.086( \pm 0.632) \\
1.063( \pm 0.614) \\
0.806( \pm 0.057) \\
0.828 \\
0.020\end{array}$ & $\begin{array}{c}0.601( \pm 0.064) \\
0.619( \pm 0.086) \\
0.585( \pm 0.113) \\
0.586( \pm 0.127) \\
0.606( \pm 0.137) \\
0.670 \\
0.241\end{array}$ & $\begin{array}{c}4.781( \pm 0.151) \\
4.425( \pm 0.472) \\
4.025( \pm 0.497) \\
3.492( \pm 0.510) \\
3.009( \pm 0.277) \\
0.992 \\
0.000\end{array}$ & $\begin{array}{l}0.198 \\
0.134 \\
0.081 \\
0.133 \\
0.105\end{array}$ & $\begin{array}{l}0.999 \\
0.999 \\
0.999 \\
0.999 \\
0.999\end{array}$ \\
\hline \multirow{2}{*}{$\begin{array}{l}\mathrm{R}^{2} \\
P>\mathrm{F}\end{array}$} & & \multicolumn{5}{|c|}{ Power Law (PL) } \\
\hline & & $K$ & $n$ & & $\mathrm{RMSE}_{\mathrm{PL}}$ & $\mathrm{R}_{\mathrm{PL}}^{2}$ \\
\hline Fermented dairy beverage & $\begin{array}{l}5 \\
10 \\
15 \\
20 \\
25\end{array}$ & $\begin{array}{c}0.765( \pm 0.306) \\
0.650( \pm 0.168) \\
0.640( \pm 0.226) \\
0.555( \pm 0.241) \\
0.423( \pm 0.186) \\
0.921 \\
0.006\end{array}$ & $\begin{array}{c}0.605( \pm 0.029) \\
0.601( \pm 0.040) \\
0.587( \pm 0.074) \\
0.584( \pm 0.095) \\
0.595( \pm 0.107) \\
0.246 \\
0.226\end{array}$ & & $\begin{array}{l}0.337 \\
0.322 \\
0.321 \\
0.282 \\
0.238\end{array}$ & $\begin{array}{l}0.995 \\
0.994 \\
0.992 \\
0.992 \\
0.992\end{array}$ \\
\hline \multirow{2}{*}{$\begin{array}{l}\mathrm{R}^{2} \\
P>\mathrm{F}\end{array}$} & & \multicolumn{5}{|c|}{ Newton's Law } \\
\hline & & $\mu$ & & & RMSE & $\mathrm{R}^{2}$ \\
\hline Fermented milk & $\begin{array}{l}5 \\
10 \\
15 \\
20 \\
25\end{array}$ & $\begin{array}{c}0.007( \pm 0.002) \\
0.006( \pm 0.001) \\
0.005( \pm 0.001) \\
0.005( \pm 0.001) \\
0.004( \pm 0.001) \\
0.973 \\
0.001\end{array}$ & & & $\begin{array}{l}0.029 \\
0.018 \\
0.018 \\
0.017 \\
0.017\end{array}$ & $\begin{array}{l}0.999 \\
0.999 \\
0.998 \\
0.998 \\
0.997\end{array}$ \\
\hline
\end{tabular}

The rheological behavior of dairy products and the influence of the different temperatures can be seen in Figure 4, which shows the relationship between appar- ent viscosities (Pa.s) and applied shear rate $\left(\mathrm{s}^{-1}\right)$. The rheological behavior shown in Figure 4a and Figure 4b is typical of non-Newtonian fluids. The non-linearity

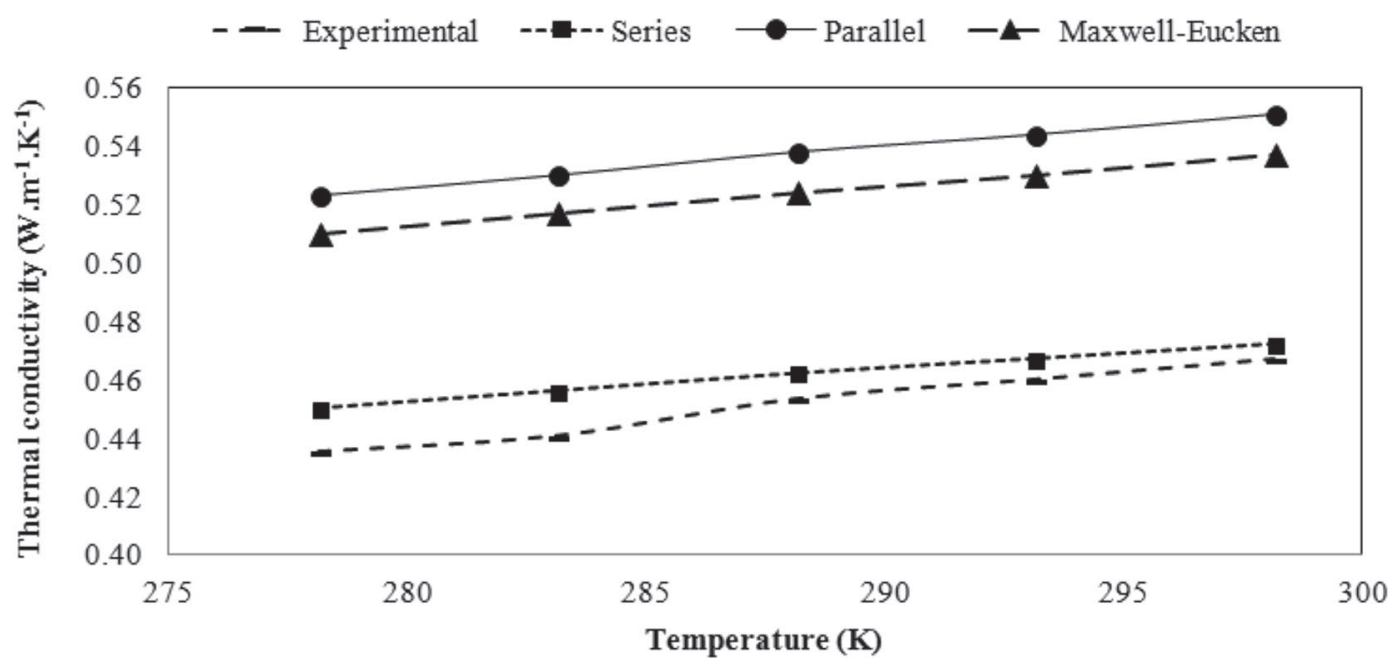

Figure 3. Experimental and theoretical (parallel, series, and Maxwell-Eucken models) thermal conductivities for yogurt. 
between apparent viscosity and shear rate is evident, such that the slope of the curve decreases with increasing shear rate. Such behavior, according to Sharma et al. (2000), is characteristic of pseudoplastic fluids. The results indicated that at all temperatures tested, the samples had shear-thinning behaviors $(n<1)$ as observed in Table 4 . The $n$ value indicates the degree of shear-thinning behavior, and in this respect, the greater the unit value, the further the fluid moves away from Newtonian behavior (Conceição et al., 2012). Mathias et al. (2013) also found shear-thinning behavior by doing a comparative study of the rheology of commercial yogurts. The value of $n$ was between 0.08 and 0.69 for the Herschel-Bulkley model, which exhibited the best suitability for flow and viscosity curves.

In Figure 4c, it can be seen that, of the 3 analyzed dairy products, fermented milk does not present a sharp degree of pseudoplasticity, because the apparent viscosity versus shear rate has an almost linear tendency. This relationship is typical of Newtonian behavior. Viscosity is one of the most important characteristics of the rheology of liquid food and is considered the internal resistance of the liquid flow. For a fixed shear rate, apparent viscosity decreases with increasing temperature for all dairy products analyzed. In Figure 4, the slopes of the curves can also be observed to decrease with increasing shear rate and with increasing temperature, showing a decrease in apparent viscosity with an increase in these 2 factors.

Ramaswamy and Basak (1991) assessed the rheological characteristics of 2 brands of yogurts, and the Herschel-Bulkley model resulted in the best fit to the experimental data. According to Ramaswamy and Basak (1991), the samples had shear-thinning and yield stress characteristics that seem to be an inherent feature of the yogurt. Yield stress, consistency index (Table 4 ), and apparent viscosity (Figure 4) decreased with increasing temperature, whereas flow index showed no tendency to vary with temperature. Penna et al. (2001) determined the rheological characteristics of 5 brands of fermented dairy beverages with measurements taken at 5 and $25^{\circ} \mathrm{C}$. The samples showed shear-thinning behavior and the power law model was the most convenient to describe the behavior of fermented dairy beverages, which was also observed in our experiments.

\section{Effect of Temperature on Apparent Viscosity}

Figure 5 shows the fit by the Arrhenius model for the apparent viscosities of yogurt, fermented dairy beverages, and fermented milk as a function of temperature at a shear rate of $27.27 \mathrm{~s}^{-1}$. The shear rate of $27.27 \mathrm{~s}^{-1}$ was chosen because the apparent viscosity values at this point are remarkably different for various tempera-
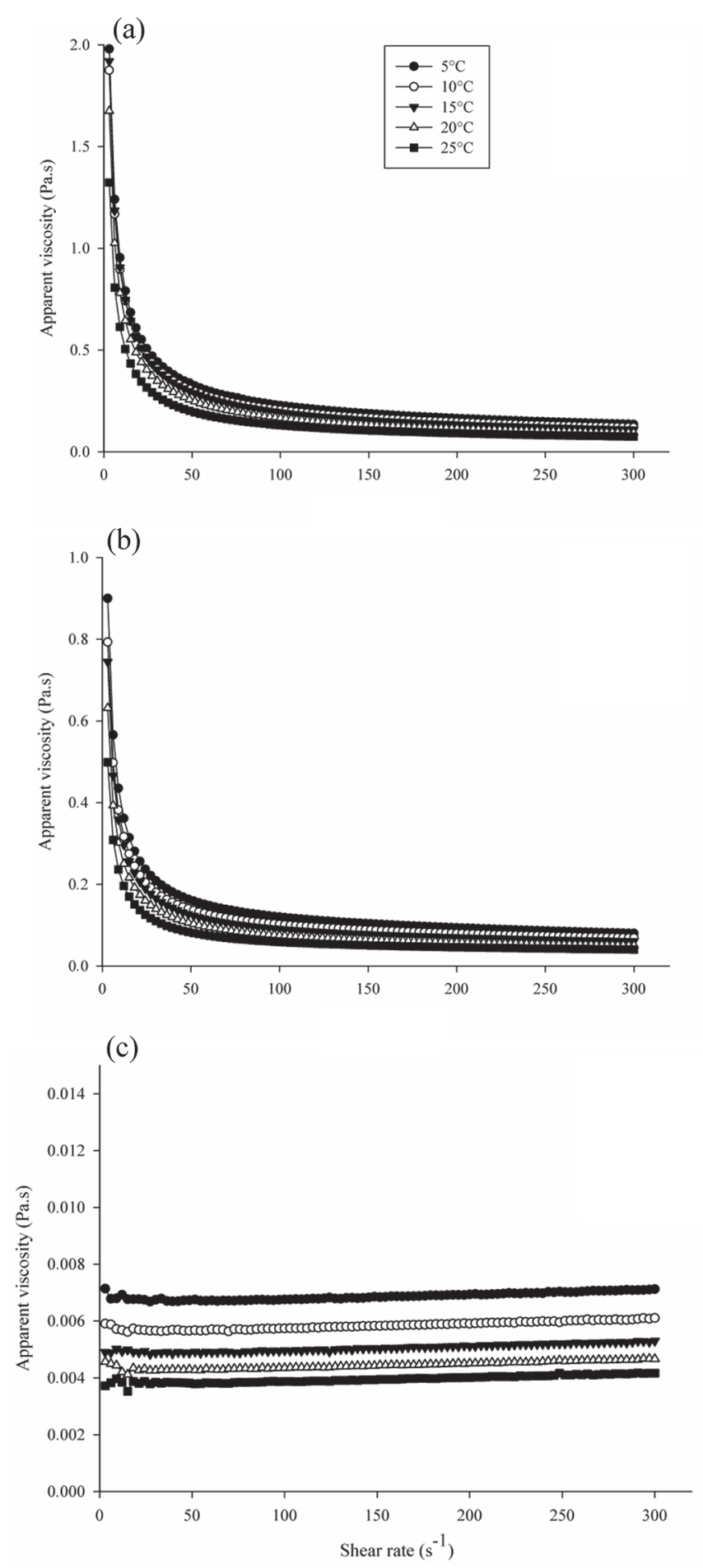

Figure 4. Relation between apparent viscosity and shear rate for (a) yogurt, (b) fermented dairy beverage, and (c) fermented milk at different temperatures.

tures. At values above a shear rate of $27.27 \mathrm{~s}^{-1}$, major changes in shear rate yield slight variations in apparent viscosity. In addition, a shear rate of $27.27 \mathrm{~s}^{-1}$ is below 


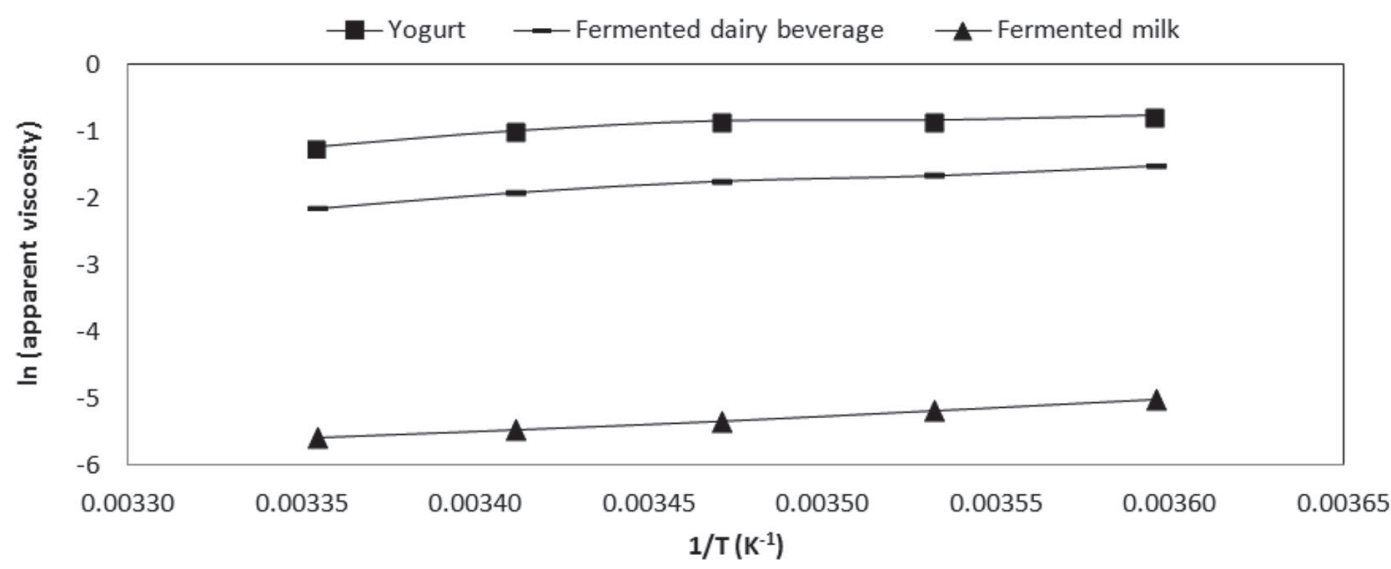

Figure 5. Application of the Arrhenius model for apparent viscosity versus temperature $(\mathrm{T})$ at a shear rate of $27.27 \mathrm{~s}^{-1}$.

the value $\left(50 \mathrm{~s}^{-1}\right)$ at which, according to Akhtar et al. (2006), oral stimuli associated with viscosity perception for low-viscosity products are usually developed.

Equations [18], [19], and [20] relate the effect of temperature on the apparent viscosity of yogurt, fermented dairy beverages, and fermented milk, respectively. The $\mathrm{R}^{2}$ values equal to or exceeding 0.8494 , for all experimental conditions, indicated good adjustment from the Arrhenius model:

$$
\begin{gathered}
\text { Yogurt: } \ln \eta_{a}=-7.2992+(1,825) T^{-1}, \\
\mathrm{R}^{2}=0.8494,
\end{gathered}
$$

Fermented dairy beverage: $\ln \eta_{a}=$

$$
-10.5590+(2,525.6) T^{-1}, \mathrm{R}^{2}=0.9612,
$$

Fermented milk: $\ln \eta_{a}=-13.4840+(2,354) T^{-1}$,

$$
\mathrm{R}^{2}=0.9967 \text {. }
$$

where $\eta_{a}$ is the apparent viscosity $(\mathrm{Pa} \cdot \mathrm{s})$ and $T$ is temperature $(\mathrm{K})$.

The use of linear equations ([18] to [20]) with equation 14 it was possible to determine the activation energy values $\left(E_{a}\right)$, and the parameter $E$ in the range of

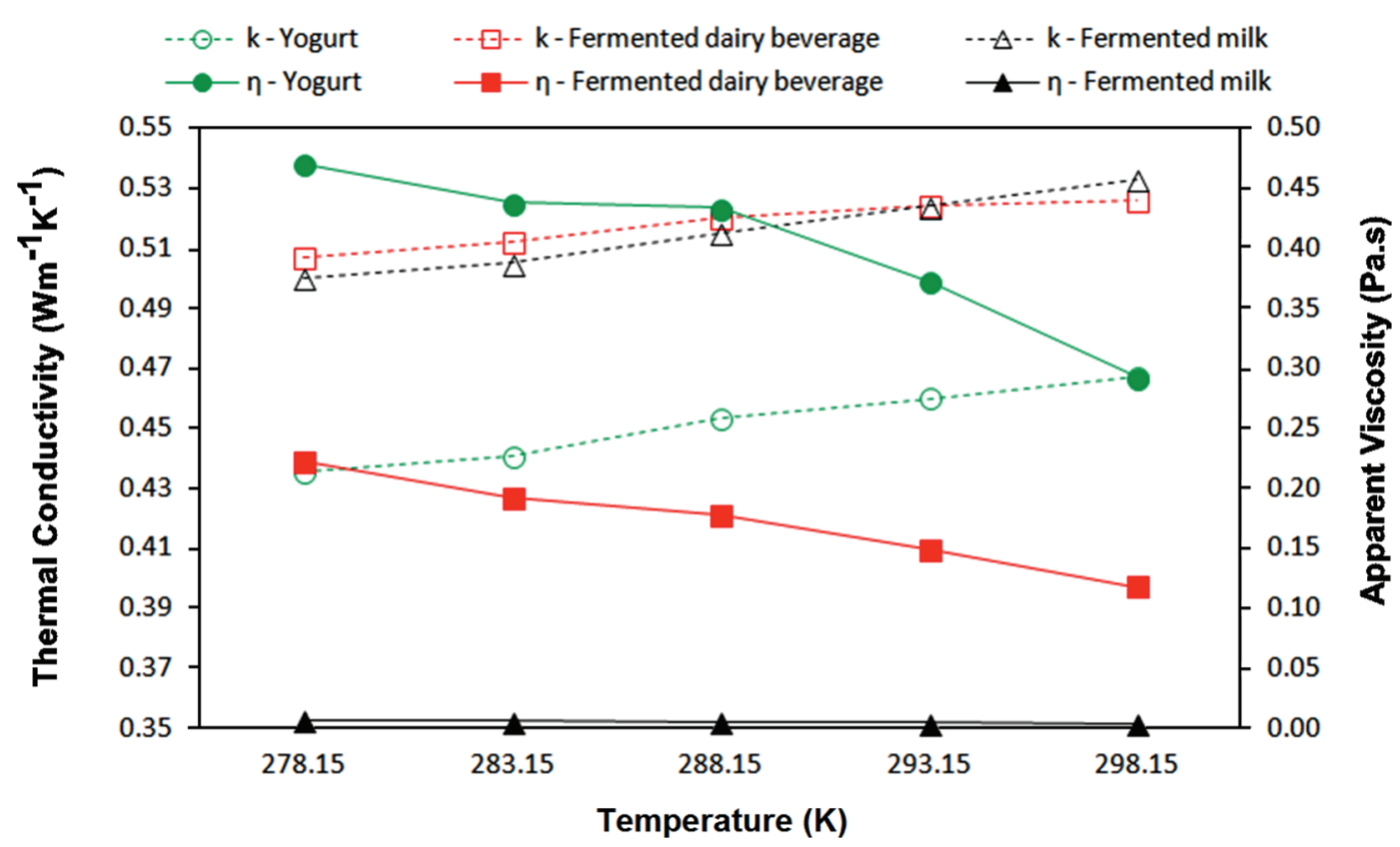

Figure 6. Thermal conductivity and apparent viscosity as a function of temperature; $k=$ thermal conductivity, $\eta_{a}=$ apparent viscosity. Color version available online. 
Table 5. Activation energy and parameter $B$ obtained by adjustment with the Arrhenius model for apparent viscosity at a shear rate of $27.27 \mathrm{~s}^{-1}$

\begin{tabular}{lcr}
\hline Product & $\begin{array}{c}\text { Activation energy } \\
\left(\mathrm{J} \cdot \mathrm{mol}^{-1}\right)^{1}\end{array}$ & \multicolumn{1}{c}{$B^{1,2}$} \\
\hline Yogurt & $15,256.190( \pm 319.765)$ & $-7.299( \pm 0.121)$ \\
Fermented dairy beverage & $20,997.838( \pm 822.404)$ & $-10.559( \pm 0.303)$ \\
Fermented milk & $19,571.156( \pm 731.854)$ & $-13.484( \pm 0.307)$ \\
\hline${ }^{1}$ Values are mean \pm SD. & \\
${ }^{2} B=$ parameter adjustment.
\end{tabular}

temperature from 298.15 to $318.15 \mathrm{~K}$. The results are shown in Table 5.

We observed that yogurt, which has a lower moisture content and thus higher soluble solids, had lower activation energy. In the temperature range of 278.15 to 298.15K, fermented dairy beverages, fermented milk, and yogurt presented a variation in apparent viscosity of $47.15,43.28$, and $37.89 \%$, respectively. According to Steffe (1996), higher values of $E_{a}$ indicate a more rapid change in viscosity with temperature. Observing the values in Table 5, the highest value of $E_{a}$ occurred in fermented dairy beverage, following by fermented milk, and then yogurt. Mathias et al. (2013), studying commercial yogurts, found $E_{a}$ between 8,995.6 and 27,781.7 $\mathrm{J} \cdot \mathrm{mol}^{-1}$. Activation energy depends on the shear rate fixed for determination of the apparent viscosity at each analysis temperature. Ramaswamy and Basak (1991) assessed the rheological characteristics of 2 brands of yogurts at a shear rate range of 0 to $500 \mathrm{~s}^{-1}$, and they evaluated $E_{a}$ at $100,200,300$, and $400 \mathrm{~s}^{-1}$. The values at various shear rates during the second and third up-curves and the 3 down-curves varied only slightly. The range of calculated values was $17,572.8$ to $21,756.8$ $\mathrm{J} \cdot \mathrm{mol}^{-1}\left(24,267.2\right.$ to $37,446.8 \mathrm{~J} \cdot \mathrm{mol}^{-1}$ in the first upcurve). We found an activation energy of $15,256.19$ $\mathrm{J} \cdot \mathrm{mol}^{-1}$ for yogurt at the fixed shear rate of $27.27 \mathrm{~s}^{-1}$.

\section{Relationship Between Thermal Conductivity and Apparent Viscosity}

To evaluate the correlation between thermal conductivity and apparent viscosity, linear equations [15] (yogurt), [16] (fermented dairy beverage), and [17] (fermented milk) were combined with Eq. [18] (yogurt), [19] (fermented dairy beverage), and [20] (fermented milk), respectively. Figures 6 and 7 show the relationship between the 2 parameters as a function of temperature for different dairy products, and Table 6 presents the equations obtained.

Analysis of Figure 6 shows that for the same temperature range, dairy products with higher moisture contents exhibited greater values for thermal conductivity
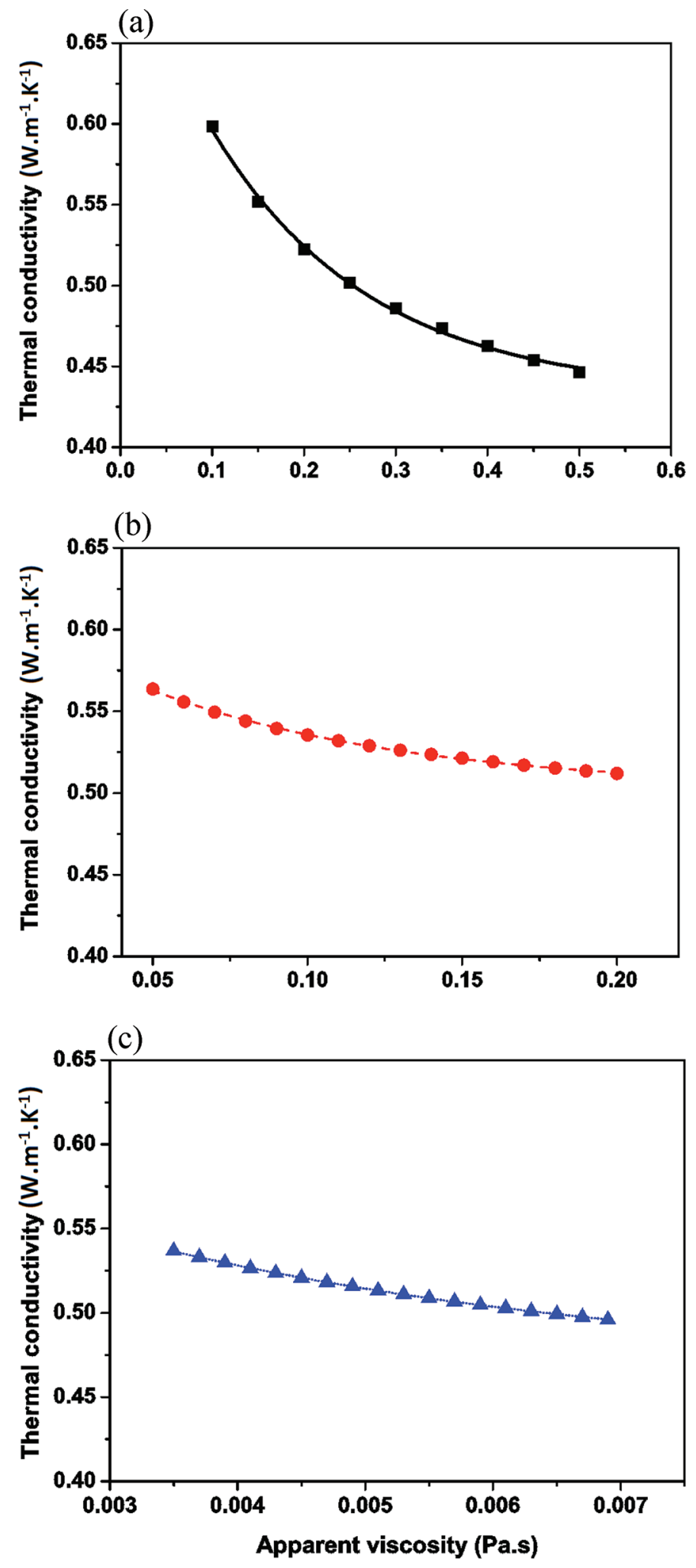

Figure 7. Thermal conductivity as a function of apparent viscosity using the equations from Table 6 for (a) yogurt, (b) fermented dairy beverage, and (c) fermented milk. Color version available online. 
Table 6. Equations of thermal conductivity as a function of the apparent viscosity for yogurt, fermented dairy beverage, and fermented milk

\begin{tabular}{ll}
\hline Product & Equation $^{1}$ \\
\hline Yogurt & $k=\left(\frac{3.1195}{\ln \eta_{a}+7.2992}\right)-0.0258$ \\
Fermented dairy beverage & $k=\left(\frac{2.5256}{\ln \eta_{a}+10.5590}\right)+0.2297$ \\
Fermented milk & $k=\left(\frac{4.0018}{\ln \eta_{a}+13.4840}\right)+0.0255$ \\
\hline
\end{tabular}

${ }^{1} k=$ thermal conductivity $\left(\mathrm{W} \cdot \mathrm{m}^{-1} \cdot \mathrm{K}^{-1}\right) ; \eta_{a}=\operatorname{apparent}$ viscosity $(\mathrm{Pa} \cdot \mathrm{s})$.

and lower values for apparent viscosity. This increase in thermal conductivity and decrease in apparent viscosity with decreasing total solids contents is related to the amount of water present. According to studies by Lee and Irvine (1997), Ikhu-Omoregbe (2009), and Qi Lin et al. (2003), for fluids that are shear thinning, thermal conductivity increases as shear rate increases and apparent viscosity decreases as shear rate increases. In Figure $4 \mathrm{a}, 4 \mathrm{~b}$, and 4c, decreases in apparent viscosity as a function of increasing shear rate were observed for all of the temperatures in the analysis; therefore, thermal conductivity increases with decreasing apparent viscosity, as can be observed in Figure 7a, 7b, and 7c for yogurt, fermented dairy beverage, and fermented milk. The magnitude of the apparent viscosity range applied to the models of Table 6 is specific for each product, as shown in Figure 7.

\section{CONCLUSIONS}

The experimental data of thermal conductivity of 3 dairy products were similar, with thermal conductivity increasing with increasing temperature. The experimental data were best fitted to the series model for all dairy products analyzed, with maximum errors of $5.94 \%$ for fermented milk, $3.45 \%$ for yogurt, and $2.66 \%$ for fermented dairy beverage. For rheological behavior, apparent viscosity decreased with increasing shear rate, and its data were correlated with temperature by the Arrhenius equation. Fermented milk showed a Newtonian trend, whereas behaviors of yogurt and fermented dairy beverages were best characterized as non-Newtonian shear thinning (pseudoplastic) and best fit by the Herschel-Bulkley and power law models, respectively. Better understanding and optimization of processes in the food industry are possible by establishing the relationship between apparent viscosity and thermal conductivity as a function of temperature. Both will be useful and important for future engineering calculations involving heat and mass transfer.

\section{ACKNOWLEDGMENTS}

The authors thank the Fundação de Amparo à Pesquisa do Estado de Minas Gerais (FAPEMIG, Brazil), the Conselho Nacional de Desenvolvimento Científico e Tecnológico (CNPq, Brazil), and Coordenação de Aperfeiçoamento de Pessoal de Nível Superior (CAPES, Brazil) for financial support for this research.

\section{REFERENCES}

Ahmed, J., H. S. Ramaswamy, and N. Hiremath. 2005. The effect of high pressure treatment on rheological characteristics and colour of mango pulp. Int. J. Food Sci. Technol. 40:885-895.

Akhtar, M., B. S. Murray, and E. Dickinson. 2006. Perception of creaminess of model oil-in-water dairy emulsions: Influence of the shear-thinning nature of a viscosity-controlling hydrocolloid. Food Hydrocoll. 20:839-847.

ASHRAE. 2002. Refrigeration Handbook. American Society of Heating, Refrigeration and Air Conditioning Engineers (ASHRAE), Atlanta, GA.

Augusto, P. E. D., A. Ibarz, and M. Cristianini. 2012. Effect of high pressure homogenization $(\mathrm{HPH})$ on the rheological properties of tomato juice: time-dependent and steady-state shear. J. Food Eng. 111:570-579.

Brazil. 2005. SISLEGIS: Sistema de Consulta à Legislação. Instrução Normativa no. 16, de 23 de agosto de 2005. (Technical rules of identity and quality whey-based drinks.) Ministério da Agricultura, Pecuária e Abastecimento, Brasilia, Brazil.

Brazil. 2007. Instrução Normativa no. 46, de 23 de outubro de 2007. (Technical regulation of identity and quality of fermented milk.) Ministério da Agricultura, Pecuária e Abastecimento, Brasilia, Brazil.

Brock, J., M. R. Nogueira, C. Zakrzevski, F. C. Corazza, M. L. Corazza, and J. V. Oliveira. 2008. Determinação experimental da viscosidade e condutividade térmica de óleos vegetais. Ciênc. Tecnol. Aliment. 28:564-570.

Carson, J. K. 2006. Review of effective thermal conductivity models for food. Int. J. Refrig. 29:958-967.

Castro, W. F., A. G. Cruz, M. S. Bisinotto, L. M. R. Guerreiro, J. A. F. Faria, H. M. A. Bolini, R. L. Cunha, and R. Deliza. 2013. Development of probiotic dairy beverages: Rheological properties and application of mathematical models in sensory evaluation. J. Dairy Sci. 96:16-25.

Chandrapala, J., and B. Zisu. 2016. Novel trends in engineered milk products. J. Dairy Res. 83:268-280.

Conceição, M. C., T. N. Fernandes, M. E. T. Prado, and J. V. Resende. 2012. Effect of sucrose and pectin addition on physical, chemical, thermal and rheological properties of frozen/thawed pineapple pulps. Korea-Aust. Rheol. J. 24:229-239.

Dawson, A., M. Rides, and J. Nottay. 2006. The effect of pressure on the thermal conductivity of polymer melts. Polym. Test. 25:268275.

Giarola, T. M. O., C. G. Pereira, and J. V. Resende. 2016. Thermal conductivity of mango pulp (Mangifera indica L.) cultivar "Ubari" in freezing temperatures. Int. J. Food Prop. 19:385-394.

Ikhu-Omoregbe, D. I. O. 2009. Effect of solid particles on the thermal conductivity of mango juice in a shear flow field. Int. J. Food Prop. $12: 885-895$.

Karsheva, M., V. Paskov, R. Tropcheva, R. Georgieva, and S. Danova. 2013. Physicochemical parameters and rheological properties of yoghurts during the storage. J. Chem. Technol. Metall. 48:483-488.

Lee, D. L., and T. F. Irvine Jr. 1997. Shear rate dependent thermal conductivity measurements of non-Newtonian fluids. Exp. Therm. Fluid Sci. 15:16-24.

Masson, M., A. Saint-Eve, J. Delarue, and D. Blumenthal. 2016. Identifying the ideal profile of French yogurts for different clusters of consumers. J. Dairy Sci. 99:3421-3433. 
Mathias, T. R. S., K. C. S. Andrade, C. L. S. Rosa, and B. A. Silva. 2013. Avaliação do comportamento reológico de diferentes iogurtes comerciais. Braz. J. Food. Technol. 16:12-20.

Mercali, G. D., J. R. Sarkis, D. P. Jaeschke, I. C. Tessaro, and L. D. F. Marczak. 2011. Physical properties of acerola and blueberry pulps. J. Food Eng. 106:283-289.

Miles, C. A., G. van Beek, and C. H. Veerkamp. 1983. Calculation of thermophysical properties of foods. Pages 269-312 in Physical Properties of Foods. R. Jowitt, F. Escher, B. Hallström, H. F. T. Meffert, W. E. L. Spiess, and G. Vos, ed. Applied Science Publishers, New York, NY.

Minim, L. A., J. S. R. Coimbra, V. P. Minim, and J. Telis-Romero. 2002. Influence of temperature and water and fat contents on the thermophysical properties of milk. J. Chem. Eng. Data 47:1488 1491.

Miyawaki, O., and R. Pongsawatmanit. 1994. Mathematical analysis of the effective thermal conductivity of food materials in the frozen state. Biosci. Biotechnol. Biochem. 58:1222-1225.

Moura, S. C. S. R., V. C. L. França, and A. M. C. B. Leal. 2005. Thermophysical properties of model solutions similar to juice-Part II. Ciênc. Tecnol. Aliment. 25:454-459.

Munir, M. T., Y. Zhang, W. Yu, D. I. Wilson, and B. R. Young. 2016. Virtual milk modelling and simulation of dairy processes. J. Dairy Sci. 99:3380-3395.

Muramatsu, Y., A. Tagawa, and T. Kasai. 2005. Thermal conductivity of several liquid foods. Food Sci. Technol. Res. 11:288-294.

Nagpal, R., P. V. Behare, M. Kumar, D. Mohania, M. Yadav, S. Jain, S. Menon, O. Parkash, F. Marotta, E. Minelli, C. J. K. Henry, and H. Yadav. 2012. Milk, milk products and disease free health: an updated overview. Crit. Rev. Food Sci. Nutr. 52:321-333.

Nindo, C. I., J. Tang, J. R. Powers, and P. S. Takhar. 2007. Rheological properties of blueberry puree for processing applications. Food Sci. Technol. (Campinas) 40:292-299.

Park, K. J., F. E. X. Murr, and M. Salvadego. 1997. Medição da condutividade térmica de milho triturado pelo método da sonda. Ciênc. Tecnol. Aliment. 17:242-247.

Park, Y. W., and G. F. W. Haenlein. 2013. Milk and Dairy Products in Human Nutrition: Production, Composition and Health. WileyBlackwell, Oxford, UK

Pelegrine, D. H., J. R. M. B. Vidal, and C. A. Gasparetto. 2000. Estudo da viscosidade aparente das polpas de manga (Keitt) e abacaxi (Pérola). Ciênc. Tecnol. Aliment. 20:128-131.
Penna, A. L. B., K. Sivieri, and M. N. Oliveira. 2001. Relation between quality and rheological properties of lactic beverages. J. Food Eng. 49:7-13.

Pereira, C. G., J. V. Resende, and T. M. O. Giarola. 2014. Relationship between the thermal conductivity and rheological behavior of acerola pulp: Effect of concentration and temperature. LWT Food Sci. Technol. 58:446-453.

Pereira, C. G., J. V. Resende, T. M. O. Giarola, S. M. Pinto, and L. R. Abreu. 2013. Thermal conductivity of milk with different levels of moisture and fat: experimental measures and prediction models. Sem. Ciênc. Agrárias 34:1153-1166.

Qi Lin, S. X., X. D. Chen, Z. D. Chen, and P. Bandoadhayay. 2003. Shear rate dependent thermal conductivity measurement of two fruit juice concentrates. J. Food Eng. 57:217-224.

Ramaswamy, H. S., and S. Basak. 1991. Rheology of stirred yogurts. J. Texture Stud. 22:231-241.

Reddy, Ch. S., and A. K. Datta. 1994. Thermophysical properties of concentrated reconstituted milk during processing. J. Food Eng. 21:31-40

Serafeimidou, A., S. Zlatanos, G. Kritikos, and A. Tourianis. 2013. Change of fatty acid profile, including conjugated linoleic acid (CLA) content, during refrigerated storage of yogurt made of cow and sheep milk. J. Food Compos. Anal. 31:24-30.

Sharma, S. K., S. J. Mulvaney, and S. S. H. Rizvi. 2000. Food Processing Engineering: Theory and Laboratory Experiments. WileyInterscience, Washington, DC.

Shori, A. B., and A. S. Baba. 2014. Comparative antioxidant activity, proteolysis and in vitro a-amylase and a-glucosidase inhibition of Allium sativum yogurts made from cow and camel milk. J. Saudi Chem. Soc. 18:456-463.

Sodini, I., F. Remeuf, S. Haddad, and G. Corrieu. 2004. The relative effect of milk base, starter, and process on yogurt texture: A review. Crit. Rev. Food Sci. Nutr. 44:113-137.

Steffe, J. F. 1996. Rheological Methods in Food Process Engineering. Freeman Press, East Lansing, MI.

Tamime, A. Y. 2006. Fermented Milks. Blackwell, Oxford, UK.

Tavman, I. H., and S. Tavman. 1999. Measurement of thermal conductivity of dairy products. J. Food Eng. 41:109-114

Walstra, P., J. T. M. Wouters, and T. J. Geurts. 2006. Dairy Science and Technology. CRC Press, Boca Raton, FL. 